$\left.(7 a)^{(1)}\right)$. The conjugative stabilization accompanying the formation of the pyrromethenic partial structure in the C.Dring region presumably promotes an eventual didehydrogenation $\operatorname{step}^{[1]]}$ to $(6)$. The same partial structure also occurs in the hexahydroporphinoid ligand system (1).

The transformation $(5) \rightarrow(6)$ is another experimental variant of Johnson's synthesis of corrinoid structures from tetrapyrrolic precursors ${ }^{[3]}$.

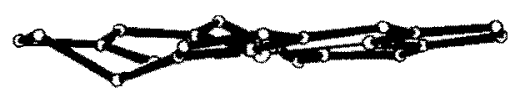

Fig. 2. Crystal structure of ctt-(6). Projection at right angles to the plane of atoms $N-21, N-22$ and $N-23$; ring-D in foreground (ligand system without substituents).

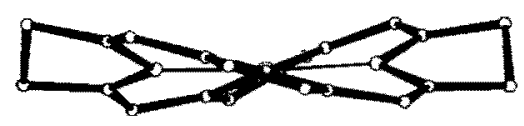

Fig. 3. Crystal structure of ictec-Nit ${ }^{1}-2,3,7,8,12,13,17,18$-octaethyl-2,3,7,8,12,13* hexahydroporphyrinate (cf. $(c / c-(5)$ in [1d]). Same projection and scale as $F$ ig 2.

Figure 2 shows the molecule cttt-(6) (cf. Fig. 1) in side view. The four coordination centres and the metal ion have essentially a coplanar arrangement; the characteristic macroring deformation observed in the nickel(II) complexes of the tetrahydro- ${ }^{[12]}$ and hexahydroporphyrin ${ }^{[1 a, d]}$ series is absent (for comparison see Fig. 3). This observation corroborates our contention that the coordination cavity of corrinoid lig and systems is closer to the spatial coordination optimum of transition metal ions such as $\mathrm{Ni}^{2+}$ than the cavity of hydroporphinoid ligand systems.

Received: January $14,1981 \quad[2707$ b IE] German version: Angew. Chem. 93, 275 (1981)

CAS Registry Nurabers:

(5), 76879-12-4; att-(6), 76880-04-1; (9), 76880-03-0; (10), 76880-02-9; (11), $76880-01-8$

[1] a) J. E. Johansen, Ch. Angst, Ch. Kratky, A. Eschenmoser, Angew. Chem. 92, 141 (1980); Angew. Chern. Int. Ed. Engl. 19, 141 (1980); b) A. Exchenmoser in $B . d$. Zagalak, W. Friedrich: Vitamin $B_{12}$ and Intrinsic Factor (Proc. 3rd Eux. Symp., Zürich), de Gruyter, Berlin 1979, p. 89, c) Ch. Angst, Dissertation, ETH Zurich (Prom. No. 6783) 1981 (in press); d) J. E. Johansen, V. Piermatie, Ch. Angst, E. Diener, Ch. Kralky, A. Eschenmoser, Angew Chem. 93, 273 (1981); Angew. Chem. Int. Ed. Engl. 20, 261 (1981); e) Y.Rasethi, B. Kräutler, A. Pfaltz, A. Eschenmoser, ibid. $89,475(1977)$ and 16,459 (1977) resp.: of. also A. I. Scott, Tetrahedron 31, 2639 (1975).

[2] This type of ligand was first observed in our laboratory by $S$. Ofnet during work on a synthesis of isobacteriochlorins. A de nowo synthesis of metal-free C,D-tetradehydrocorrins will be published later (cr. $S$. Ofner, Dissertation. ETH Zürich 1981).

[3] a) A.W. Johnson, Chem. Soc. Rev, 9, 125 (1980), and literature cited therein; D. Dolphin, R. L. N. Harris, J. L. Huppatz. A. W. Johnson, J. T. Kay, J. Chem. Soc. C 1966, 30; b) D. Dicker, R. Grigg, A. W. Johnson, H. Pinnock, $K$ Richardsan, $P$. van den Brock, ibid. $C 1971,536$.

[4] For nomenclature, see $R$. Bonnett in $D$. Dolphin: The Porphyrins. Acadenic Press. New York 1978, Vol. 1, pp. 1-27; J. E. Merritt, K. L. Loening. Pure Appi. Chem. 51, 2251 (1979).

[5] Colorless needles, $m . p_{3}=166^{\circ} \mathrm{C}$ (under $\mathrm{N}_{2}$ in evacuated capillary) characterized by $\mathrm{MS}$. ' $\mathrm{H}$ - and ${ }^{\prime} \mathrm{C}-\mathrm{NMR}$; prepared by reduction of $1,2,3,7,8,12,13,17,18$-nonamethyl-10,23-dihydrobilin dihydrobromide with $\mathrm{NaBH}_{4}$ in $80 \%$ methanol (yield $51 \%$ ). For the synthesis of the starting mate riai, a modified procedure of that described by $A . F$. Mironov, $O$. D. Popova, Kh. Kh. Alarkon, V. M. Bairamov, R. P. Evstigneeva, Zh. Org. Khim 15, $1086(1979)$; J, Org. Chem. USSR 15,970 (1979) was used. For details, ct. [1c].

[6] a) HPLC: Partisil 5; pentane-dimethoxyethane-triethylamine $200: 2: 1$; ) present to $21 \%$ in the mixture of diastereomers $(6)$.

[7] a) Identified by comparison of UV/VIS and mass spectra with those of (9) [7b]; this compound was prepared [1 c] from nonamethyl-10,23-dihydrobilin dihydtobromide by Johnson+cyclization [3b]. b) D. A. Clarke, R. Grigg. $R$ L. N. Harris, A. W. Johnson, I. T. Kay, K. W. Shellon, J. Chem. Soc. C 1967 1648 .

[8] UV $/ \mathrm{VIS}$ spectrum $\left(\mathrm{CH}_{2} \mathrm{Cl}_{2}\right)$ of a crystalline precipitate characterized by MS and 'H-NMR spectroscopy; for isolation and constitutional assignment of [1c]; a) binary mixture of diastereomers (10): $\lambda_{\text {max }}=295 \mathrm{~nm}(\mathrm{gg}=4.20), 330$ sh (4.11), 360 sh (4.23), $408(4.57), 476$ sh $(3.72), 545(3.52), 625$ sh $(3.60)$, 657 sh $(3.72), 695(3.86), 758(4.23)$; b) diastereomer (11) from nonamethyl. $5,15,21,24$-tetrahydrobilin; (cf. [1 1]): $\lambda_{\max }=303 \mathrm{~nm}(\mathrm{~g} \in=425), 399(4.33)$, $455(4.03), 508(3.87), 675(3.90)$.

[9] a) We thank Dr. $R$. Schwesinger for a sample of TBD, of also [id]. reference [4]; b) $R$, Schwesinger, unpublished results.

[10] $\mathrm{E} g$. using $15 \cdot 10^{-2} \mathrm{M}(5)$ in $p$-xylene, 1.5 mole equivalents DBU/HOAC (2:1), 5 mole equivalents $\mathrm{Ni}(\mathrm{OAc})_{2}+4 \mathrm{H}_{2} \mathrm{O}$, anaerobic conditions, $16 \mathrm{~h}$, $140^{\circ} \mathrm{C}$, produced inter alia, a mixture of diasiereomeric $\mathrm{Nin}{ }^{\prime \prime}$-octamethylisobacteriochlorinates (I) in 45 yicld using the same conditons, but with four times as much buffer, led lapart from ca. 20\% isobacteriochlotinate, ca. $10 \%$ chlorinate and traces of 61 il $1016 \%$ of a product fraction, which according to UV/VIS, MS and H-NMR data surprisingly must be a Nill $\{, 2,3,7,8,12,\{3,17,18$-nonamethyl $(1)-1,7,8,20$-tetrahydroporphyrinate; for details ef $[1 c]$

111 The nature of the hydrogen acceptor remains unknown. The reaction se quence does not proceed via the didehydrogenated nonamethyl-5, 15,21,24 tetrahydrobilin, because this gives practically no 6 w wder the reaction conditions of Scheme 2; under milder conditions (11 mole equivalents TBD, 1 mole equivalent $\mathrm{Ni}\left(\mathrm{OAc}_{2}, 4 \mathrm{H}_{2} \mathrm{O}\right.$, benzene, anaerobic $25 \mathrm{~h}, 60^{\circ} \mathrm{C}$, dias tereomers of types (11) and (6) are formed, yields $c a .15$ and $12 \%$ respec tively $(\mathrm{cl} / \mathrm{lcl})$.

[12] Ch Kratky, Ch. Angst, J. E. Johansen, Angew, Chem. 93, 204 (1981); Angew. Chem. Int Ed. Engl. 20, 211 (1981).

\section{Electrophilic Reactions of Aryl- and Heteroaryl(trimethyl)silanes with a Remarkable Nucleophilic Catalysis $\left.{ }^{[* *}\right]$}

\section{By Franz Effenberger and Wolfgang Spiegler ${ }^{* 1}$ \\ Dedicated to Professor Gerhard Pfleiderer on the occasion of his 60th birthday}

Eaborn et al." have shown that the facile displacement of the trimethylsilyl moiety by electrophiles is a decisive factor in the protodesilylation of aryl(trimethyl)silanes; on the basis of kinetic data, they have proposed a mechanism for this reaction analogous to that for electrophilic aromatic substitution. The very high ipso rate factors for a series of electrophilic desilylation processes ${ }^{[2]}$ gave rise to the expectation that aryl(trimethyl)silanes ${ }^{[3]}$ might also be successfully employed for synthetic purposes; this was confirmed by a regiospecific route to polysubstituted benzenes via aryl(trimethyl)silanes reported recently ${ }^{[4]}$.

Our own investigations of the acylation of aryl(trimethyl)silanes ${ }^{|5|}$, and reports in the literature on reactions of aldehydes with trimethylsilyl(pentahalo)benzenes ${ }^{[6 a]}$ and heteroaryl(trimethyl)silanes ${ }^{[6 b]}$, have led us to the assumption that a mechanism different from that formulated by $E a$ born ${ }^{1 t]}$ might be operative in these cases. For this pathway, the breaking of the aryl-silyl bond-with at least partial evolution of aryl anions-would be rate-limiting; substituents which stabilize negative charges should therefore enhance the reactivity of aryl(trimethyl)silanes towards electrophiles.

But 2-nitrophenyl(trimethyl)silane (1a) does not react with benzaldehyde even upon heating to $100^{\circ} \mathrm{C}$ in dimethylformamide (DMF) for three days. If, however, potassium tert-butanolate is added in catalytic amounts, electrophilic

[*] Prof. Dr. F, Effenberger, Dipl.Chem. W. Spiegler Institut fur Organische Chemie der Universitat Pfaffenwaldring 55, D.7000 Stutgari 80 (Germany)

[**] This work was supported by the Fonds der Chemischen industrie, We wish to thank H. Kottmann for experimental assistance. Electrophilic Aromatic Substitution, Part 20.-Part 19: F. Effenberger, G. König. K. Klenk, Chem. $\mathrm{Ber}_{4}, 114,926(1981)$. 
substitution proceeds smoothly even at $-60^{\circ} \mathrm{C}$, (2a) being formed within $1 \mathrm{~h}$ in $92 \%$ yield. Analogously, from a series of substituted phenyl(trimethyl)silanes $(1 a)-(1 h)$ and benzaldehyde, the benzhydrylsilyl ethers $(2 a)-(2 h)$ or, after hydrolysis, the benzhydrols (3) were obtained (Table 1).
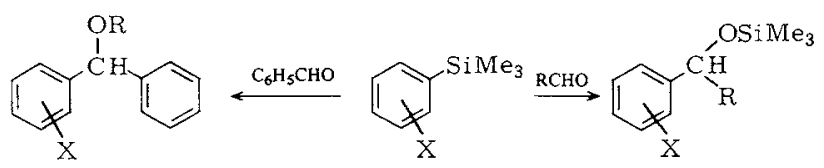

(2), $\mathrm{R}=\mathrm{Me}_{3} \mathrm{Si}$

(3), $\mathrm{R}=\mathrm{H}$

(I)

(4)
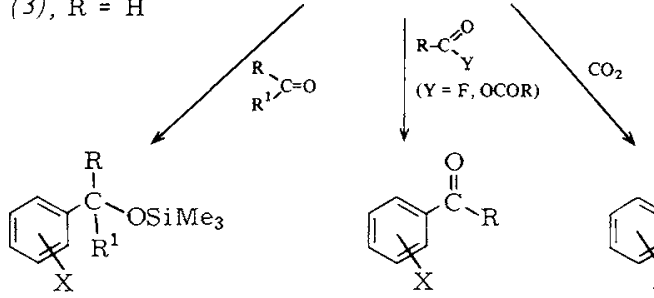

(5), R, R $R^{1}$ Alkyl

Aryl

(6). $\mathrm{R}=$ Alky

Aryl $-60^{\circ} \mathrm{C}$. Since the heteroaryl(trimethyl)silanes are readily accessible via cycloaddition reactions ${ }^{[3]}$, this method allows the introduction of substituents into heterocyclic substrates with high regioselectivity ${ }^{[9]}$.

The reaction will be of special preparative advantage in those cases where organometallic derivatives cannot be employed because of the presence of reactive functional groups in the molecule (nitro or carbonyl compounds) or because of secondary reactions, e.g. formation of dehydroarenes from halogen compounds or isomerization to more stable anions.

\section{Experimental:}

(2a): Potassium tert-butanolate $(83 \mathrm{mg}, 0.74 \mathrm{mmol})$ is added to a constantly stirred mixture of $(1 a)^{[10]}(3.91 \mathrm{~g}, 20 \mathrm{mmol})$ and benzaldehyde $(2.12 \mathrm{~g}, 20 \mathrm{mmol})$ in $25 \mathrm{~cm}^{3} \mathrm{DMF}$ at room temperature. The solutions warms slightly and turns red; as indicated by GLC, the reaction is complete after $1 \mathrm{~h}$. The catalyst is filtered off, and the DMF distilled off. Upon fractional distillation, the oily residue yields $4.81 \mathrm{~g}(80 \%)(2 a)$, b.p. $136-138^{\circ} \mathrm{C} / 0.1$ torr. 'H-NMR $\left(\mathrm{CDCl}_{3}\right)$ : $\delta=0.07$ (s, $9 \mathrm{H}), 6.57(\mathrm{~s}, \mathrm{H}), 7.20-8.00(\mathrm{~m}, 9 \mathrm{H})$.

Received: September 8th, 1980 [Z 706 a IE] German version: Angew. Chem. 93, 287 (1981)

[1] C. Eaborn, I. Organomet. Chem. 100, 43 (1975).

[2] a) C. L. Perrin, I. Org. Chem. 36,420 (1971); b) S. R. Hartshorn. Chem. Soc. Rev. 3, 167 (1974).

[3] D. Habich. F. Effenberger, Synthesis 1979, 841 .

14] G. Félix, J. Dunoguès, R. Calas, Angew. Chem. 91, 430 (1979); Angew. Chem. Int. Ed. Engl. 18, 402 (1979).

[5] D. Häbich, Dissertation, Universität Stuttgart 1977.

[6] a) A. F. Webb, D. S. Sethi, H. Gilman, J. Organomet. Chem. 21, P61 (1970). b) F. H. Pinkerton. S. F. Thames, J. Heterocycl. Chem. 6, 433 (1969); ibid. 8 . 257 (1971): ibid. 9. 67 (1972); T. Ogawa, M. Yasui, M. Matsui, Agr. Biol. Chem. 34. $970(1970)$

[7] a) G. B. Barlin, D. D. Perrin, Q. Rev. Chem. Soc. 20.75 (1966), b) C.Eaborn, G. Seconi, J. Chem. Soc. Perkin Trans. II 1976, 925; C. Eaborn. J. G. Stamper, G. Seconi, J. Organomet. Chem. 150, C 23 (1978).

[8] Tse-Lok Ho: Hard and Soft Acids and Bases Principle in Organic Chemistry. Academic Press. New York 1977.

[9] A. Krebs, intended Dissertation, Universität Stuttgart 1981

[10] C. Eaborn, D. R. M. Walton, D. J. Young, J. Chern. Soc. B 1969. 15

For the nitro- and chlorophenyl(trimethyl)silanes, the relative reactivity correlates well with the $\sigma^{1}$-substituent constants ${ }^{[7 a]}$, but diverges significantly from the order of stabilization of the phenyl anions which would be essential intermediates for a nucleophilic desilylation ${ }^{[7 b]}$. The $\sigma^{1}$ correlation holds also for the other arylsilyl substrates $(1 c)-(1 f)$ in Table 1; the remarkable increase in reactivity from $(1 d)$ to (1f) is similarly mirrored in the substituent constants. This clearly indicates that the electrophile participates significantly in the rate-limiting step of the reactions reported here-in contrast to normal nucleophilic desilylation ${ }^{[7 b]}$. Since "hard" bases have proven especially effective nucleophilic catalysts $\left(\mathrm{KOC}\left(\mathrm{CH}_{3}\right)_{3}, \mathrm{KF}\right.$, CsF, tetraalkylammonium fluoride, $\mathrm{KOAc})^{[8]}$, one must assume that interaction of the catalyst with the silicon is the decisive factor for the reaction.

We have also extended the reaction to substituted benzaldehydes and aliphatic aldehydes, to ketones, acyl fluorides and carboxylic acid anhydrides as well as to carbon dioxide; the respective products, secondary (4) and tertiary benzyl alcohols (5), aryl ketones (6) and substituted benzoic acids (7), are obtained, at least in part, in excellent yields.

The scope of the procedure can be further widened by variation of the arylsilyl substrate. From 2-trimethylsilylbenzthiazole and benzaldehyde, for instance, the substitution product is formed in $78 \%$ yield, only after heating to $160^{\circ} \mathrm{C}$ for $40 \mathrm{~h}^{16 \mathrm{~b}]}$; in the presence of $1 \mathrm{~mol}-\%$ of potassium tert-butanolate, $91 \%$ of the product is obtained after $15 \mathrm{~min}$ at

\section{Nucleophilic Catalysis of Reactions of Tricarbonyl(trimethylsilylarene)chromium Complexes with Electrophiles ${ }^{\left.{ }^{* *}\right]}$}

\section{By Franz Effenberger and Klaus Schöllkopf $\mathrm{f}^{* *}$ \\ Dedicated to Professor Gerhard Pfleiderer on the occasion of his 60 th birthday}

Electrophilic substitution of aryl(trimethyl)silanes having electron-donating substituents, e.g. alkyl- or aminophenyl(trimethyl)silanes, is not amenable to nucleophilic cataly-

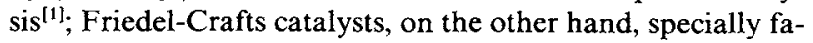
cilitate reactions of such substrates with electrophiles. In this case, however, the directing influence of the substituents often overrides the tendency of the trimethylsilyl moiety to ipsosubstitution, and regular $\mathrm{H}$-substitution results ${ }^{[2]}$. Recent investigations have established the electron-withdrawing effect

[*] Prof. Dr. F. Effenberger, Dipl.-Chem. K. Schöllkopf Institut für Organische Chemie der Universität Pfaffenwaldring 55, D-7000 Stuttgart 80 (Germany)

[**] This work was supported by the Fonds der Chemischen Industrie. We thank Herr Steegmuller for experimental assistance: NATO research grant No. 1602 is gratefully acknowledged. Electrophilic aromatic substitution. Part 21.-Part 20: [1]. 